\title{
ENUNCIAÇÕES ESTÉTICAS EM VÍDEOS ESCOLARES NA CULTURA DIGITAL: por uma outra forma de olhar os estudos midiáticos na escola
}

\author{
CINTIA INES BOLL
}

Universidade Federal do Rio Grande do Sul. Departamento de Estudos Especializados e programa de Pós-Graduação em Educação e Ciências. ORCID:https://orcid.org/0000-0003-1089-3271. E-mail: cintia.boll@ufrgs.br

\section{DANIEL NEHME MULLER}

Escola Técnica Santo Inácio e Faculdade Monteiro Lobato. Desenvolvedor de software e sócio da Conexum Sistemas Computacionais Inteligentes Ltda. Doutor em Ciência da Computação pela Universidade Federal do Rio Grande do Sul (2006). ORCID: https://orcid.org/0000-0003-4845-4557. E-mail: daniel@conexum.com.br

\section{MARISTELA ROSSATO}

Universidade de Brasília. Instituto de Psicologia - Departamento de Psicologia Escolar e Desenvolvimento. Professora do Programa de Pós-Graduação Psicologia do Desenvolvimento e Escolar. Doutorado em Educação pela Universidade de Brasília (2009). ORCID: https://orcid.org/0000-0001-6457-9005. E-mail: maristelarossato@gmail.com

\section{MARGARETE AXT}

Professora Titular da Universidade Federal do Rio Grande do Sul. Aposentada, atuando como colaboradora convidada nos Programas de Pós-Graduação em Educação (PPGEdu) e em Informática na Educação (PPGIE).

Doutorado em Lingüística e Letras pela Pontifícia Universidade Católica do Rio Grande do Sul (1994). ORCID: https://orcid.org/0000-0002-5117-9894. E-mail: maaxt@ufrgs.br

\section{WILSA MARIA RAMOS}

Universidade de Brasília. Instituto de Psicologia - Departamento de Psicologia Escolar e Desenvolvimento. Professora do Programa de Pós-Graduação em Processos de Desenvolvimento humano. Pós-doutorado em Psicologia (Universitat de Barcelona). Doutorado em Psicologia (UNB, 2005). ORCID: https://orcid.org/0000-0002-3029-1684. E-mail: wilsa@unb.br 


\section{ENUNCIAÇÕES ESTÉTICAS EM VÍDEOS ESCOLARES NA CULTURA DIGITAL: Por uma outra forma de olhar os estudos midiáticos na escola}

Uma típica comunicação contemporânea é cada dia mais carregada pelo componente estético enunciado em muitos trabalhos escolares juvenis em vídeos definidos como paródias no YouTube. Nesse sentido, esse ensaio propõe a reflexão de uma típica produção contemporânea juvenil baseada na narrativa videográfica. Trata-se de uma comunicação dialógica onde quem vê algo, vê e (re)age atribuindo sentidos que não só técnica e/ou criticamente, pois que o faz com todos seus poros, dilatando seu olhar com todas as pupilas materiais e imateriais de seu corpo, pele e alma. Uma produção que se mantém ativada na relação dinâmica também com fruidores/leitores dessas comunicações e que, em sintonia com a cultura digital, convida-nos a investigar a relação discursiva enunciada esteticamente nessas narrativas dispostas nas paródias videográficas escolares.

Palavras chave: Enunciação Estética. Trabalhos Escolares. Paródias Videográficas Escolares. Cultura Digital. Vídeos Juvenis.

\section{AESTHETIC ENUNCIATION IN SCHOOL VIDEOS IN DIGITAL CULTURE: For another way of looking at media studies at school}

A typical contemporary communication is every day more loaded by the aesthetic enunciation component in many youth schoolwork videos defined as parodies on YouTube. Thus, this paper proposes a reflection of a typical youthful contemporary production based on videographic narrative. It is a dialogical communication where those who see something, see and (re)act by assigning meanings that not only technically and/or critically, because they do it with all their pores, dilating their look with all the material and immaterial eye pupils of their body, skin and soul. A production that remains active in the dynamic relationship also fruitors/ readers of these communications and in line with the digital culture, invites us to investigate the discursive relation aesthetically enunciated these narratives arranged in school videographic parodies.

Keywords: Aesthetic Enunciation. Schoolwork. School Video Parodies. Digital culture. Youth Videos.

\section{ENUNCIACIONES ESTÉTICAS EN VIDEOS ESCOLARES EN CULTURA DIGITAL: Para otra forma de ver los estudios de medios en la escuela}

La comunicación contemporánea típica está cada vez más cargada por el componente estético establecido en muchas obras de escuelas juveniles en videos definidos como parodias en YouTube. Por lo tanto, este documento propone una reflexión de una típica producción contemporánea juvenil basado en la narrativa videográfica. Es una comunicación dialógica donde aquellos que ven algo, ven y (re)actúan asignando significados que no solo técnica y/o críticamente, porque lo hacen con todos sus poros, dilatando su mirada con todas las pupilas materiales y inmateriales de su cuerpo, piel y alma. Una producción que permanece activa en la relación dinámica también con fruidores/lectores de estas comunicaciones y que, en sintonía con la cultura digital, nos invita a investigar la relación discursiva estéticamente expresada en estas narrativas organizadas en parodias videográficas.

Palabras-clave: Enunciación estética. Trabajos escolares. Video parodias escolares. Cultura digital. Videos Juveniles. 


\section{ENUNCIAÇÕES ESTÉTICAS EM VÍDEOS ESCOLARES NA CULTURA DIGITAL: por uma outra forma de olhar os estudos midiáticos na escola}

\section{Introdução}

A educação midiática tem sido costumeiramente vinculada às propostas pedagógicas ou de um lugar da crítica, da análise metódica do que se vê e lê, do que se estuda em conteúdos escolares, ou de um lugar da análise técnica entre software e hardware. Nesse aspecto as questões estruturais-ideológicas e tecnológicas são contempladas ao mesmo tempo em que outra, a do componente estético, subsume, inexiste: ela pulsa, ela vive, mas parece (ainda) não existir na educação midiática. Uma variedade instigante do singular componente estético presente nas paródias videográficas escolares, o mesmo componente estético que na poesia faz parceria com a palavra, na composição de um texto midiático de matriz digital: o vídeo. Este se apresenta em parceria ao mesmo tempo com a palavra, o som (musicais ou ruídos) e outros materiais visualmente perceptíveis (gestos, mímica, vestuário, personagens, cenários).

Em tempos de cultura digital, é necessário compreender os motivos pelos quais um jovem se debruça na composição de vídeos para a internet, para usá-los em seus trabalhos escolares, publicizando sua produção a fruidores/leitores desconhecidos e não previsíveis, para além do grupo escolar e do professor de uma disciplina curricular. Mais do que isso: é preciso compreender como este jovem instaura um processo de comunicação, encarnado em/nesse objeto digital: há uma estética própria a essa enunciação juvenil.

\section{Educação midiática e as análises técnicas e/ou críticas}

A educação midiática, muito especialmente pela popularização das tecnologias móveis, tem sido marcada por variáveis que não só técnica e não só crítica. A produção e a distribuição da informação estão mais volúveis e voláteis em novas mídias e/ou mídias interativas e/ou mídias digitais. Se reconhece um fluxo marcado por uma matriz digital que tem componentes de natureza colaborativos, interativos, distributivos e especialmente estéticos em prontidão para fazer parceria com os currículos escolares. Essa parceria é indutora de outras possibilidades de leituras, cada dia mais apreciativas/fruidoras; e cada dia menos analíticas e passíveis de certos e errados. 
Manter o foco da educação midiática, discutindo apenas habilidades técnicas e críticas, não destaca a complexidade da participação juvenil nessa matriz digital proporcionada pela abertura do fluxo informacional em redes sociais de amplo alcance. A emissão, a transversalidade e a personalização da produção, assim como do consumo, de uma diversidade de narrativas em sons, textos e imagens têm sido cada dia mais enfatizadas por esse coletivo juvenil, também no espaço escolar. Trata-se de outro modo de existir e de comunicar na escola, conectados que estão às narrativas de vídeos caseiros, muitos registrados como "paródias" e trabalhos escolares.

$\mathrm{Na}$ composição estética da narrativa videográfica juvenil busca-se uma expressiva intencionalidade em roupas, sapatos, em trejeitos da fala ou em gestos. Um corpo juvenil que implica tentativas materiais de superação imanente que existem nessa criação e dela totalmente dependem. São valores originalmente de conteúdos que, em conexão, expressam individual e coletivamente sentidos singulares e únicos: a voz se apresenta como pluralidade em uma "subjetividade polifônica" (GUATTARI, 2012), tal qual uma "multiplicidade de eus no corpo subjetivo" que se estende a um "eu" dilatado:

Então, a cultura e a comunicação digital, que colocam em crise esta perspectiva coletiva, conseguem afirmar o processo conectivo que significa que a individualidade, que prefiro chamar de multivíduo, se multiplica, se amplia, explode. Uma multiplicidade de eus no corpo subjetivo. Essa condição múltipla favorece a proliferação dos eus o que acaba por desenvolver outro tipo de identidade, fluida e pluralizada, que coloca, potencialmente em crise, as formas perversas e tradicionais do dualismo. (CANEVACCI, 2009, p.9)

Esse jovem videográfico e multivíduo isola e recorta fragmentos de conteúdos éticos e cognitivos do cotidiano tanto escolar quanto da cultura (regional, digital...) de espectro mais amplo, aparentemente dispersos em um primeiro olhar, instituindo-os como valores na tentativa de estabelecer uma relação dialógica entre as vozes enunciadas pela via das palavras e as vozes estésicas, sonoras e visuais. Confirmando um contexto apreciativo onde esse valor transita, o jovem busca pela convergência de sentidos comunicativos entoados pela narrativa composicional em ações que dependem tanto da situação mais imediata em que se encontra a produção narrativa, quanto da situação social-cultural em que se encontra.

Burgess e Green (2009) definem este tipo de composição produzida a partir do cotidiano (incluindo bilhetes, fotos, vídeos caseiros e outros), bem como seu compartilhamento em redes sociais em coexistência à produção das grandes agências midiáticas, de criatividade vernacular, ou criatividade do cotidiano. Esse conceito diferencia-se do que Jenkins (2008) define como narrativa 
transmidiática - expressão utilizada por ele para nomear práticas comerciais de convergência de processos criativos na cultura. Mas embora diferenciadas, tanto a narrativa transmidiática quanto a criatividade do cotidiano proliferam sustentadas por toda uma comunidade participativa. A interface do YouTube colabora no movimento dessa expressividade narrativa em direção a uma territorialidade informacional.

O conceito de criatividade vernacular ou do cotidiano deve ser especialmente considerado enquanto gênero digital do efêmero nos processos criativos/inventivos da cultura juvenil, caseira e escolar. Na educação midiática, esse digital efêmero parece estar muito próximo ao que ocorre no improviso de contar histórias, um lugar vinculado à produção composicional inusitada de sentidos dispersos, constituindo uma típica criatividade do cotidiano, a ser acolhida em sua especificidade, intencionalidade e singularidade, como sugere Axt (2004).

O jovem que se expressa na atividade videográfica caseira escolar apresenta um fluxo comunicativo próprio, enredado à cultura digital, movendo-se em direção ao evento histórico de sua ação, de suas escolhas no ato realizado. O caráter singular dessas narrativas juvenis nos possibilita apreciá-las em seus processos criativos na cultura digital.

Segundo Setton (2009, p.72) "é isso o que se espera para uma discussão inovadora no campo das TICs, pois que assim é possível focar o processo de produção e não o produto desse processo". Na educação brasileira, até recentemente, temos uma história muito mais próxima às imagens fotográficas, aos livros e à mídia impressa, do que às imagens fílmicas. Ainda é muito comum encontrar nas salas de aula recortes e colagens em trabalhos enquanto que os vídeos ficam restritos a um ou outro momento específico que estão sendo revolucionadas pelas mídias móveis, celulares, tablets e smartphones.

Nos anos 1970, no Brasil, os vídeos em estilo de aula-documentário dos telecursos, ou o uso de novelas educativas, inauguraram tentativas de incluir a videografia aos objetivos pedagógicos. No entanto, os vídeos nos espaços escolares começaram a conquistar professores e alunos somente no final da década de 80, quando foi ao ar a TV Escola, para que, enfim, os vídeos se tornassem recursos possíveis na maioria das salas de aulas das escolas públicas brasileiras. Mais recentemente, algumas ações de cunho público e mais abrangentes, tais como os Programas Mais Educação (MEC), Ensino Médio Inovador (MEC) e Ponto de Cultura (MinC), possibilitaram também que cada escola implementasse a educação midiática através de cursos e atividades específicas dirigidos a esse fim. Também o Projeto CIVITAS/UFRGS tem favorecido esta prática no Ensino Fundamental, anos iniciais, conforme indicado em Axt e Martins (2008). 
Com ações cada vez mais contundentes, por parte também dos órgãos públicos, a linguagem videográfica começa a ser fortalecida nas salas de aula quando em ação com a educação midiática e com o ansioso imaginário juvenil que, cada dia mais, parece desejar ser um dos protagonistas desses vídeos. Muitas experiências têm sido publicizadas em blogs e vlogs pessoais na internet, independentes do acompanhamento pedagógico: mais do que esperar receber orientações e oportunidades, os próprios alunos se lançam no desafio de encontrá-los na rede.

Ao que parece, os jovens não têm se preocupado com quem tem acesso às suas produções, se é ou não seu conhecido, ou com quem estão se comunicando através das redes sociais como Facebook, Twitter, Instagram... Formam comunidades, com base em proximidade de interesses temáticos, ou de iniciativas coletivas de ações ou de produção, sem mesmo ter encontrado pessoalmente, fisicamente, um ao outro. Além disso, fazem parte de comunidades também tão diferentes quanto ecléticas, possivelmente na tentativa de dar conta da fluidez, multiplicidade e diversidade identitária de que fala Canevacci (2008). Surpreendentemente, os vídeos digitais compartilhados em blogs e vlogs, além de inúmeros, são extremamente interessantes, não só por se apresentarem nessa matriz digital sem restrições de acesso, mas também por nos desafiarem para além de interpretações técnicas e/ou críticas de uma educação midiática.

\section{Para além de interpretações técnicas e/ou críticas: a paródia videográfica escolar como matriz polifônica de sentidos}

Os vídeos digitais publicados no YouTube, nomeados pelos estudantes como Trabalhos de Português, Trabalhos de História, etc., catalogados como paródias já em suas tags no YouTube apresentam uma esteticidade peculiar: paródias, movimentadas e carentes de olhares pedagógicos, se apresentam não só em sua intencionalidade criativa, mas especialmente em variados estilos. Ora essa narrativa paródica nos convida a rir, ora a ironizar. De qualquer maneira se percebe que a proposta que nos movimenta em direção ao que foi parodiado nos mantém dialogando também com outros elementos criando ressonâncias inusitadas e originais.

As narrativas paródicas nos trabalhos escolares, das quais falamos, se apresentam em sentidos que escapam de uma possibilidade de análise apenas técnica e/ou crítica: como os professores avaliariam grosserias, sátiras e outras apropriações textuais típicas de uma paródia, tais como o pastiche (a imitação), o travestimento (mascaramento) e o grotesco (absurdo)? Ou seria essa narrativa paródica, em sua complexidade enunciativa, descartada pelo olhar docente que só busca no vídeo o conteúdo escolar? 
Uma característica dessa narrativa paródica juvenil é a possibilidade de produzir outros sentidos - sentidos polifônicos em canto paralelo - a partir de uma obra que atingiu conhecimento público, notoriedade cultural. A narrativa paródica só é compreendida através da semelhança e correspondência ao que já se conhece na obra original - o que é parodiado precisa estar na cultura do cotidiano para ser devidamente identificada. Para Bakhtin (2000) a composição estética envolve componentes, materiais e imateriais, e participantes em uma enunciação. A cultura do cotidiano, entre grosserias e absurdos, se oferece para servir de inspiração à paródia no contexto da composição juvenil. O vídeo, portanto, em seu conjunto expressivo, é esse típico enunciado estético juvenil em tempos de cultura digital.

Não só a publicidade, a moda, a arte e a arquitetura, mas também a escola apresenta o seu componente estético nessa metrópole que Canevacci (2008) define como metrópole comunicacional enquanto corpo expandido, entrelaçado e hibridizado em fluxos comunicativos contemporâneos. Nela, os edifícios, prédios, shoppings são corpos comunicacionais em extensão que, somatizados pelos fluxos da tecnocomunicação, atravessam poros e olhos desses corpos comunicacionais, num sentido profundo da multiperspectiva do fazer-se ver. A polifonia está tanto no componente quanto no fluxo comunicacional. A narrativa paródica videográfica juvenil recolhe fragmentos dispersos de sentidos e de conteúdos para instaurar valores composicionais na fronteira entre a escola e a cultura digital, produzindo um corpo sonoro-visual-textual singular e, ao mesmo tempo, polifônico e convergente.

Os componentes estéticos ou valores, quando entonados em parceria com grosserias, sátiras e outras apropriações textuais típicas de uma narrativa paródica, se comportam tal como os atratores para os fetiches visuais na metrópole comunicacional descrito por Canevacci (2008). Esses atratores, de alto valor fetish, absorvem todas as atenções. Empregado em sua potência comunicativa, o atrator é fragmento simbólico que fixa sentidos e que, em algum momento do fluxo comunicativo, paralisa e instiga a (tentar) decifrá-lo. Para Canevacci (2008), os atratores são códigos visuais erópticos que, difundidos na comunicação, concentram olhares e empoderam enigmas e sentidos, até então silenciados, orientando e liberando desejo estético numa relação indissociável com a alteridade-dialógica.

As paródias videográficas escolares podem apresentar os atratores enquanto um traço estilístico (porque expressão singular) e sistemático (porque recorrente), convocando o espectador à produção de sentidos. Neste contexto das paródias videográficas escolares o atrator está presente em elementos que se destacam no cenário, à exempla das echarpes, nos óculos, nos sapatos, nos cobertores listrados... O atrator também pode estar presente em outros componentes como sons, escritas e expressões culturais, inclusive algumas tipicamente desse mundo juvenil e escolar,

\footnotetext{
P/U $a$ i $S$ Salvador, v. 4, n. 2, p.132-144, mai./ago. 2019
} 
dispostos no encontro cruzado de conteúdos heterogêneos: tudo o que se quer é magnetizar o espectador.

O componente estético nas paródias videográficas escolares só pode ser apreciado num modo contemplativo, compreendido como acolhimento ativo e amoroso do outro nessa relação. Existe uma constante busca de um acabamento provisório e efêmero heterogêneo, disperso e fragmentado, que dá corpo a diferentes vozes numa composição expressiva e estilística, recheada, ao mesmo tempo e paradoxalmente, de clichês e de inusitados provocativos frequentemente grotescos. O componente estético da narrativa videográfica juvenil em trabalhos escolares apresenta valores encarnados, dispersos em palavras e em matérias dinâmicas, em estesias sonoras e visuais, que se tramam e se conectam em composição, sempre sui generis, do qual os próprios clichês fazem parte.

\section{Narrativa paródica grotesca em forma videográfica escolar}

A narrativa paródica grotesca em forma videográfica escolar se assume como enunciação estética engendrando conteúdo interior e objetivação exterior em direção a um interlocutor/fruidor/espectador ativo e participante. Um espect-autor (BOLL, 2013), na intersecção com o conceito de espect-ator em Canevacci (2008), e de autoria em Bakhtin (1988), se apresenta em composição sine qua non para que possa ser apreciada.

Espect-autores se encontram neste espaço comum de expressão e de contemplação (ativa), configurando essa enunciação estética em uma dinâmica comunicativa dialógica, que, segundo Bakhtin, o objeto estético não existe antes da criação, nem independente dela (1988). Na paródia, a intencionalidade do processo criativo opera na produção de um "canto paralelo" em relação a determinado original, "destruindo", desta maneira, o sentido estabelecido no original pela produção estilizada ostensiva do duplo sentido, ou do sentido paralelo. A composição paródica cria corpo na medida do processo de destruição da estilização do outro (original). A escolha intencional de elementos - fragmentos de conteúdo -, do original, isolados e recortados pelo autor da paródia para essa destruição estilizada, dá origem à composição paródica.

No processo de estilização da paródia videográfica escolar, o elemento estilizado é mostrado em parceria com elementos contemporâneos, recriando a própria linguagem parodiada a partir de desejos, conflitos, resistências..., em variedades de procedimentos. Mesmo quando o foco é um original da literatura clássica brasileira, a composição do estilo busca seus elementos nos personagens da vida real contemporânea, como programas televisivos e nas músicas populares, carregando a marca de seus criadores: sua intencionalidade ideológica.

Nas praças públicas da Idade Média, por exemplo, o grotesco se apresentou em seus mais diversos gêneros e variações estilísticas, em formas e símbolos de animais, bufões, malandros e tolos, para fazer com que as obscenidades proibidas na cultura dominante, dos clérigos e senhores feudais em composições avizinhadas à cultura carnavalesca incitassem o riso (Bakhtin, 2008). Hoje temos uma composição avizinhada 
à escola onde a intencionalidade juvenil, mascarada de certa maneira, resgata a cultura carnavalesca, buscando modos de provocar o riso pela comicidade paródica e, em muitas situações, também grotesca. Tem-se, então, um rito escolar, o dos trabalhos escolares, apresentando-se na praça pública da internet, seus vídeos na forma de uma narrativa paródica grotesca.

Trabalhos escolares definidos pelos jovens como "paródias" se oferecem como enigmas para serem decifrados por um professor com "boa vontade" (ECO, 2013), cúmplice dessas ressonâncias irônicas, dos risos debochados, escrachados, entre os corpos comunicacionais em seus movimentos sonoros-visuaistextuais. Trabalhos escolares sui generis em aparente descrédito às regras escolares.

\section{Um recorte apreciativo das paródias videográficas escolares}

Enquanto foco temático, a obra original "São Bernardo" de Graciliano Ramos, apresenta-se com o contexto ampliado de um reality show nos moldes do programa Big Brother Brasil - BBB. Esse programa, conhecido da cultura brasileira contemporânea pelo tom confessional historicizado e publicizado de cada jogador que dele participa, dá vida ao personagem Paulo Honório da obra de Graciliano Ramos, recriado na paródia videográfica escolar como "Paulão" como um jogador no BBB (Big Brother Brasil).

A produção desse vídeo faz parte do site compartilhamento do YouTube'. Trata-se de uma página pública, de acesso irrestrito, que se apresenta como "Trabalho de Português: Paródia do Livro de São Bernardo". Na abertura do vídeo aparece o seguinte comentário: "Decidimos fazer uma mistura de Big Brother Brasil com o resumo do livro". Esse vídeo foi postado dia 20 de junho de 2011, por Gabriel Dorfman, na categoria "viagens e eventos".

Em determinado momento do referido reality show existe um "confessionário" onde cada jogador deve expressar a verdade sobre as questões colocadas. O personagem Paulo Honório (na obra clássica de Graciliano Ramos) ou Paulão (no programa popularmente intitulado BBB), estilizado pelos traços persecutórios típicos descritos no livro, conta sua vida em tom confessional de um típico romantismo piegas - tal como ocorre no livro. Nessa narração se apresentam elementos grotescos inusitados tais como a letra de um funk carioca "sou foda na cama eu te esculacho" ou a fala da principal personagem "enfiei a faca nele", onde o homicídio e as conotações sexuais de submissão se sobressaem entre escritas, falas e imagens.

Os elementos da música - palavras cantadas e enredo - se apresentam grosseiros, brutos, com "palavrões" e conotações sexuais de submissão como protagonizados por Paulo Honório, na obra de Graciliano Ramos. O machismo, como elemento dessa composição, justificado pelo homicídio em defesa da sua dignidade máscula, dando o tom dos elementos contemporâneos, mostrando uma intencionalidade ideológica.

${ }^{1}$ É possível acessá-lo em https://www.youtube.com/watch?v=S9kErQ4f6vQ

p/U $\operatorname{ai} S$ Salvador, v. 4, n. 2, p.132-144, mai./ago. 2019 
Os nomes com as fotos dos atores e personagens, pelo menos duas para cada jogador e pelo menos uma em atitude grosseira, são apresentados na introdução em uma composição que faz unir os elementos palavra-cantada e palavra-escrita na tela digital. Vale também ressaltar que o elemento da palavra-cantada na letra da música une-se ao protagonista da paródia videográfica, Paulo Honório (no livro) ou Paulão (no $\mathrm{BBB})$, que apresenta no funk carioca apresenta traição e machismo no tema.

O canto paralelo da paródia videográfica, que denunciam o machismo em tom intimista, confessional e público, em uma típica exposição de sua elucubração inconsequente, imaginando que poderia ter a chance de participar de um programa de reality show. Surpreendentemente, ou nem tanto para um apreciador atento, o protagonista Paulão foi julgado como ELIMINADO, impossibilitado de participar. Paralelamente, o popular e o clássico se unem para referendar a intencionalidade ideológica de um mau caráter.

Os elementos, aparentemente heterogêneos, distribuídos ao longo do vídeo, compõem o atrator que suspende e captura a atenção do expectador, por meio da fragmentação da obra de Graciliano e do BBB em pequenos pedaços, que se unem para compor uma narrativa grotesca. Uma narrativa grotesca romântica que ora se apresentava intimista, enclausurada nos pensamentos de Paulão, ora se apresentava como narrativa grotesca medieval, onde o "terrível" - do homicídio e do suicídio - aparecia mais uma vez em tom de "bobagem alegre". Aos espect-autores, a intencionalidade ideológica se movimentou entre sentidos do machismo e dos papéis femininos assumidos pelas personagens. Uma intencionalidade que apresenta, entre elementos contemporâneos e não-contemporâneos, a tragédia de uma relação baseada em desconfiança, desamor, interesses, que Paulão anuncia como “apenas negócios”, de um protagonista persecutório.

No vídeo, as palavras faladas, as legendas escritas, a entonação da voz, a grosseria nos gestos e na composição das roupas, assim como os apetrechos dispostos pelos cenários, apresentam-se como elementos de ocultação de sentidos - os atratores -, tendo em vista uma intencionalidade juvenil a ser desvendada pelo espectador de boa vontade e atento: o espect-autor.

Entendemos os atratores, nessa composição juvenil, como códigos de acesso aos processos criativos, tanto para que o jovem possa compor a sua paródia videográfica escolar, quanto para que o espect-autor, seu professor e colegas, possam ingressar nela, decifrando os sentidos do enigma, agora encarnados em canto paralelo. Nos vídeos escolares, podemos afirmar que,

O atrator, enigmático e paradoxal, se produz no cruzamento de conteúdos fragmentários, dispersos e heterogêneos, gerando momentaneamente, pelo inusitado dos múltiplos e excessivos cruzamentos de sentido, uma espécie de parada virtual no tempo, um entre-tempos intervalar que faz emergir um nano-momento de suspensão de todo o sentido, gerando um non-sense ou um vazio de sentidos, em que nos perguntamos: 'o que quer dizer esta combinação?'. É na busca do sentido, no entre-tempos, que o espectador se faz espect-autor, tensionando-se ao atrator-enigma. (BOLL, 2019) 
E esse enigma é justamente o atrator em movimento no vídeo, que, ao mesmo tempo, oculta e espera o sentido.

O efeito dessa montagem narrativa paródica estudada aqui se configura pelo riso, um riso perpassado pelo tom de denúncia, às vezes grotesco, mas, ao mesmo tempo, de criação poética. Essa paródia videográfica juvenil canta simultaneamente o mundo escolar e o mundo contemporâneo, em toda sua potência, mas também em suas mazelas grotescas.

Apresenta o grotesco avizinhado à realidade da violência doméstica e ao pieguismo do auto arrependimento de um homem "machista" e seus atos destrutivos cometidos em vista de fantasias persecutórias, ciúme e ganância. Uma comunicação juvenil amarrada, cantada em trabalho escolar que não é tecida em tom sério, mas é composicionalmente dolorida, triste/alegre e grotesca, que quer fazer rir, porém em riso tenso da denúncia escrachada de um tempo vivo e atual.

\section{Algumas considerações}

Os gêneros cômicos, nos diz Bakhtin (1988), sempre foram os mais livres e menos regulamentados: o espírito oficial e a burocracia revestidos pela seriedade não conseguiram degenerar o riso. Nas narrativas paródicas grotescas, o atrator entonado aproxima o que antes não combinava, destrói o que antes era combinação perfeita. Onde antes se tinha apenas laços de vizinhança habituais, passa-se a ter agora, pela paródia videográfica escolar, laços de vizinhança inesperados. Sentidos inusitados, antes silenciados, explodem numa miríade polissêmica de novos sentidos paralelos cuja tônica é o riso cômico, nervoso e debochado.

A função estética no vídeo escolar apreciado encontra-se, em nosso entendimento, na composição intencional de vizinhanças inesperadas entre conteúdos heterogêneos, e via de regra, dispersos, com vistas a fazer rir. E é o atrator que carrega (literalmente) o grotesco para cenário educativo, pelo atravessamento composicional de roupas, jeitos e trejeitos que, em movimento, sugam nossos olhares espect-autores em direção às multivozes que ali se exibem obrigando-nos a uma posição enunciativa de interpretação (autoral).

A narrativa paródica juvenil, em nosso contexto contemporâneo digital, traz em sua composição (estética) uma plena dialogicidade acoplada a uma linguagem poética grotesca, em que o jovem afirma sua potência ao dizer-se parte desse mundo. Um mundo onde ele não pode ser reduzido a um número, a um consumidor, a um certo/errado, ele é parte desse paradoxo composicional entre convergência transmidiática e processos criativos a partir do cotidiano - é ele o artista:

O artista é, precisamente, [...] aquele que não se limita a participar da vida (pratica, social, política, moral, religiosa) e a compreendê-la apenas do seu interior, mas aquele que também a ama do exterior - no ponto em que ela não existe para si mesma, em que está voltada para fora e requer uma atividade

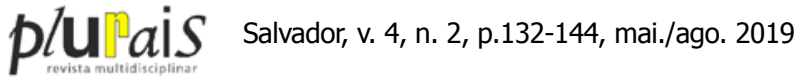


situada fora de si mesma e do sentido. [...] encontrar o meio de aproximar-se da vida pelo lado de fora, é esta a tarefa do artista. (BAKHTIN, 2000, p.205)

$\mathrm{Na}$ tentativa de compreender a transgressão juvenil em trabalhos escolares em forma de vídeo, o detalhe do grotesco é um elemento fundamental no processo dessa enunciação estética, clivada entre a convergência consumista e a produção singularizada. Sim, consumidores. Sim produtores. Sim espectautores, pois não há mais somente as paródias avizinhadas inesperadamente aos vídeos, à escola e aos trabalhos escolares, há também trabalhos escolares avizinhados inesperadamente a uma enunciação estética de natureza cômica grotesca: a narrativa paródica grotesca.

Uma típica comunicação dialógica, onde quem vê algo, vê e (re)age atribuindo sentidos, técnica e/ou criticamente, o faz com todos seus poros, dilatando seu olhar com todas as pupilas materiais e imateriais de seu corpo, pele e alma. Também atribui sentidos pelo tensionamento que emerge dos múltiplos enunciados em cruzamento, na liberação dos muitos "eus" e suas vozes. Como num jogo, cada voz tensiona todas as vozes desafiantes, não sendo nunca uma jogada à parte, solitária. Uma produção que se mantém ativa na relação dinâmica também com fruidores/leitores dessas comunicações e que, em sintonia com a cultura digital, convida-nos a apreciar essas enunciações estéticas em vídeos escolares no YouTube. Há, portanto, outra forma de compreender os estudos sobre a educação midiática na escola.

\section{REFERÊNCIAS}

AXT, M. Civitas, a cidade viva: ou de um espaço para o acontecimento-invenção na escola. Educação e Realidade, Porto Alegre, v. 29, n.02, p. 219-235, 2004.

; MARTINS, M. Coexistir na diferença: De quando a formação em serviço pensa modos de habitar a sala de aula. In: TRINDADE, Iole Maria Faviero. (Org.). Múltiplas Alfabetizações e Alfabetismos. , v. 1, p. 133-158. Porto Alegre: Editora da UFRGS, 2008, v. 1, p. 133-158.

BAKHTIN, M.M. A Cultura Popular na Idade Média. São Paulo: Hucitec, 2008.

Questões de Literatura e de Estética. São Paulo: Unesp, 1988.

. Estética da Criação Verbal. São Paulo: Martins Fontes, 2000.

BOLL, C.I. Enunciação Estética Juvenil em Vídeos Escolares no YouTube. Tese de Doutorado em Educação - Faculdade de Educação. UFRGS, Porto Alegre, 2013. 117f.

;AXT, M.; MULLER,D.N Aplicativos mobile pedagógicos para a Educação Básica: da possibilidade dialógica para uma inteligência conectiva. In: TRINDADE, S. (Org.) Educação e Humanidades Digitais: aprendizagens, tecnologias e cibercultura. Coimbra: Coimbra Editora, (no prelo). 
BURGESS, J.; GREEN, J. YouTube e a Revolução Digital: como o maior fenômeno da cultura participativa transformou a mídia e a sociedade. São Paulo: Aleph, 2009.

CANEVACCI, M. A Comunicação Entre Corpos e Metrópoles. Signos do Consumo, v.1. n.1, jan.-jul de 2009.

. Fetichismos Visuais: corpos erópticos e metrópole comunicacional. São Paulo: Ateliê Editorial, 2008.

ECO, U. Confissões de Um Jovem Romancista. São Paulo: Cosac Naify, 2013.

GUATTARI, F. CAOSMOSE: um novo paradigma estético. Rio de Janeiro: Editora 34. Editado em 1992. 2. ed. em 2012.

JENKINS, H. Cultura da Convergência. São Paulo: Aleph, 2008.

SETTON, M. da G. J. Juventude, Mídias e TIC. in SPOSITO, M.P. (coord.) Estado da Arte sobre juventude na pós-graduação brasileira: educação, ciências sociais e serviço social (19992006), vol. 2. Belo Horizonte, MG: Argvmentvm, 2009.

Enviado em: 17 de julho de 2019

Apreciado em: 30 de julho de 2019

Inserido em: 01 de agosto de 2019 